\title{
STRATEGIES, ORGANIZATIONAL COMMITMENT AND LEADERSHIP STYLES IN SMEs
}

\author{
Daniel RUSU \\ Bucharest University of Economic Studies, Bucharest Romania, \\ rusumdaniel@gmail.com
}

\begin{abstract}
Among the practitioners as well as among the researchers in the field of management, the theme of leadership enjoys a boundless and special interest. Regarding the results of the management within the SMEs, a very important role is played by the management. The aim of this paper is to examine the relationship between organizational commitment and the leadership dimensions of Bass (1985) (transactional, transformational and laissez faire) but also several outcome variables (leadership efficiency, employee satisfaction with the leader, additional effort employees). According to the methodology and approach, this is a systematic review of the literature. This review describes the Full Range Leadership Model (Bass, 1985) and the conceptual framework, which include laissez-faire leadership, transactional leadership, and transformational leadership. In this section, the characteristics and abilities of transformational leaders were discussed. The leadership section concludes with discussions of previous research on transformational leadership. This review also provides an analysis of the literature on organizational engagement. The various definitions of organizational commitment as well as the three components of the commitment model are set out. The paper presents the results and antecedents of organizational commitment resulting from previous research and concludes with a discussion related to the impact of transformational leadership on the organizational commitment of employees.
\end{abstract}

Keywords: Organizational Commitment, SMEs, Leadership Styles, Transformational Leadership, Strategy

DOI: https://doi.org/10.24818/beman/2021.11.4-03

\section{INTRODUCTION}

Undoubtedly, in the field of management, one of the most debated issues is represented by managerial training as well as its impact on the performance of the organization (Nicolescu et. al., 2012). Extensive international research has been conducted in the field of management in the last 50 years. In the opinion of Kumar and Kaptan, (2007), leadership issues are particularly important for organizational success and for this reason there has been an overwhelming emphasis on researchers. According to Lussier and Achua, (2007), it is particularly difficult for members of organizations to sustain their competitive advantage, productivity and profitability without having an efficient and especially strategic leadership. Leadership is the process by which an executive can influence, guide and direct the work and behavior of others to achieve specific goals in a given situation and the ability of a manager to 
induce subordinates to work with zeal and confidence, and can fully influence the behavior of others. (Ioniță and Stoica, 2019). Moreover, in the opinion of Wu (2009), in influencing the functioning of the members of an organization, an important variable is defined by the leadership style, considering that in the field of management, leadership styles, in recent years, have become an important subject of study. Leadership is, by its nature, a much more powerful integrator than associated processes or technology. Management, unlike the rather rigid and specific technology, re-presents a generic and flexible integrator because it acts on individual intelligence transforming it into organizational intelligence as well as on individual knowledge transforming it into organizational knowledge (Mandruleanu, 2012). An important predictor of performance within an organization is defined as leadership style (Bass et al., 2003). It is necessary for the leader to be obedient but also confident in relation to others, in order to provide hypothetical failures or gaps in the functioning of the business, because he is the only one fully responsible for the entire activity (Trifu, 2018). Over time, there has been extensive research on organizational engagement, as evidenced by a review of the literature (Mathieu and Zajac, 1990; Meyer and Parfyonova, 2010; Meyer et al., 2002; Mowday et al., 1982; Porter et al.., 1974). The beneficial effects generated by organizational commitment are well recognized in the management literature. A particularly important variable in understanding the behavior of employees in workplaces within organizations is precisely the commitment identified in the organizational literature, repeatedly. Impact on several work-related attributes, such as absenteeism (Porter et al., 1974) but also the intention to stay (Chew and Chan, 2008; Mathieu and Zajac, 1990; Meyer et al., 2002; Porter et al., 1974) is generated by commitment, according to some researchers previous. The profile of SME managers, at individual level, is a complex one, having a variety of attitudes, skills and aptitudes to have a real success at work. In addition to the essential characteristics necessary for a top management position (communication skills, managerial decision making, strategic thinking) they must be complemented by other critical skills such as motivating others, negotiation, mentoring or stress management (Ibanescu, Racolta-Paina and lonescu, 2015). Given the fact that employee organizations are able to avoid the collateral costs with absenteeism but also with high turnover rate, this is particularly relevant. Moreover, employees can show a greater predisposition to performance as well as better motivation at work (Abdul Rashid et al., 2003; Chen et al., 2006; Riketta, 2002; Samad, 2005; Yousef, 2000). Usually, the evolution of contemporary companies towards sustainable organizations faces a major challenge, represented by the resistance to change both among employees and managers, as well as employees. From this point of view, leadership plays a significant role both in reducing resistance to change and in accelerating this transition process. Today, leadership is becoming an increasingly challenging issue, especially in small and medium-sized enterprises (SMEs) located in developing countries, where 
management, as well as decision-making, still represent empirical processes (Tapurica, 2012). While in SMEs it has not been considered a topic of interest to researchers, most theories approach leadership as a general concept within large companies or within project teams. The most significant difference, compared to a large company, is related to the way in which leadership is applied and perceived in a small or medium enterprise (SME), this being due to the direct influence that the owner has on its employees (Mihai et. al., 2017). The engine of economic progress and sustainable development of a nation is represented by entrepreneurial activity. A precarious level of social protection, unfair access to health care and the education system, poverty and unequal distribution of wealth are strong reasons for developing creative ideas in sustainable and successful businesses (Paunescu et. al., 2018).

This article highlights the link between organizational commitment and several outcome variables (leadership effectiveness, employee satisfaction with leadership, additional employee effort) and the dimensions of Bass's (1985) leadership (laissez-faire and transformation, transactional).

\section{THE CONCEPTUAL FRAMEWORK OF THE STUDY}

Bass's (1985) full-range model underlies this analysis. Laissez-faire, transactional but also transformative styles represent the favorite leadership styles that are identified by Bass. Two types of transactional behavior (passive management by exception and contingent reward) are included in Bass's initial theory. Another transactional behavior called active management as an exception to the theory as well as another transformational behavior defined as inspirational motivation were added during a review of this theory. The defining elements for the charismatic leadership are represented by the inspirational motivation but also by the idealized influence. In the opinion of Bass and Avolio, (2004), the idealized influence attributions but also the idealized influence behavior represent the 2 components of the idealized influence behavior. Idealized influential behavior is an evolution of the initial conceptualization of Full Range Leadership (Bass, 1985). Based on Full Range Leadership Theory, MLQ was developed by Bass (1985). Bass and Avolio (2004) updated the MLQ (5X Short) which is the latest version of the MLQ. In the opinion of Bass and Avolio (2004), in order to evaluate the laissezfaire, transactional but also transformative leadership styles, MLQ was formulated. Passive management by exception, contingent reward and active management by exception are the three behavioral components of transactional management. The non-leadership factor is represented by laissez-faire. The evaluation of the three result factors: the satisfaction of the employees towards the leader, the effectiveness of the leader as well as the additional effort is made by using MLQ. 


\section{LAISSEZ-FAIRE DRIVING STYLE}

According to Yulk (2010), the absence of effective leadership is characterized by laissez-faire. According to Gill, (2006), in order to characterize the leadership that refuses to intervene, does not pursue, ignores problems and avoids making and implementing decisions, laissez-faire is used. Laissez-faire leadership is demonstrated by leaders who avoid taking responsibility for leadership and are undecided. According to Sadler (2003), laissez-faire leaders do not show any initiative in terms of interaction with group members and at the same time play a passive role in group business. They are not involved in the development of subordinates, avoid making decisions and do not give guidance.

\section{TRANSACTIONAL LEADERSHIP STYLE}

The transactional management model was developed by Burns (1978). According to Burns (1978), this occurs when, in the intention of exchanging precious things that could be psychological, political or economic, a person connects with other people. Although the relationship does not go beyond the stage of exchanging appreciated benefits, in Burns' opinion both sides manifest related goals. In the opinion of Erhart and Nauma (2004), an extra-role behavior of followers is unlikely to be triggered by the relationship. According to Burns (1978), in a continuous and reciprocal search for a higher goal, it is not the leader who binds the next together.

In conclusion, Bass (1985) developed the theory of transactional management and at the same time extended Burns' activity. In Bass's opinion, the exchange or transaction that takes place between followers, colleagues and leaders characterizes transactional leadership. According to Bass and Avolio (1994), the exchange is based on a discussion between followers and leaders regarding the rewards but also the requirements that, if they meet these conditions, followers will receive. For requirements to be advanced on both sides, valuables are exchanged by transactional leaders with followers (Ivey and Kline, 2010). In the opinion of Bass et al. (2003), to avoid punishment for failure to achieve goals or for non-performance or in exchange for rewards and praise, followers meet the leader's requirement. In this way, because it is attentive to the achievement of specific objectives or objectives, the transactional management is a realistic one (Aarons, 2006).

According to Northouse (2007), transactional leaders are far from paying attention to an employee's personal development. On the other hand, these transaction-oriented leaders are much more focused on achieving goals. In Burns's view (1978), providing punishments for negative performance or rewards for positive performance and also clarifying tasks are directions on which transactional leaders focus. For performance but also for behaviors that coincide with the expectations and goals of leaders, 
followers are rewarded by leaders (Bass and Avolio, 1994; Northouse, 2007). For the necessary influence on the followers to obtain the desired results, the transactional leaders use all their power (Avery, 2004; Bass, 1985).

According to Politis (2002), transactional leaders generate trust in their followers and subsequently motivate their followers in obtaining the expected performances. From a study conducted on a number of 72 platoons from the US military, Bass et al. (2003) noted that transactional management generates a highly efficient management that becomes essential for achieving successful performance. According to the study, platoon leaders apply transactional leadership with an emphasis on very clear performance expectations and standards. Later, leaders offer members of the platoon rewards for accomplishing certain specific goals. According to Bass et al., (2003), transactional leaders, by providing clarity to expectations, contribute positively to optimizing performance.

\subsection{The main components in transactional management}

The process of exchange between subordinates and leaders defines the contingent reward. The rewards pursued to fulfill the tasks but also the results of these tasks to be performed are negotiated between subordinates and leaders. According to Boerner et al. (2007), they intervene only in exceptional circumstances and act as monitors both passive and active management applied by exceptional leaders, in contrast. The practice through which leaders intervene to correct the performance of the followers either after the appearance of the problem (passive management by exception) or in anticipation of the problem (active management by exception) is represented by the management by exception.

Contingent reward. According to Bass et al. (2003), the selection of appropriate motivating rewards, performance expectations as well as clear goal setting are achieved by the leader in transactional management. In the opinion of Gill (2006), considering that they set the rewards for performance, the performance standard but also the objectives, transactional leaders tend to use the managerial style more and more. The agreement between followers and leaders regarding the standards and performance objectives to be met define the contingent reward.

Active management by exception. According to Gill (2006), a leader who imposes procedures, rules and corrects errors, actively monitors employees' jobs in order to look for deviations but also errors, sets the performance standard and objectives defines active management by exception. According to Wu et al., (2006), exceptionally active management involves those leaders who take the initiative to condemn employee misconduct as well as to observe employee behavior. Leaders intervene when problems or mistakes arise but also monitor employees' performance systematically. 
Passive management by exception. Leaders do not react to problems systematically in passive management through exceptional leadership. The standard is set by leaders who expect problems or errors to occur and then subsequently reluctantly interfere. When employees make mistakes in their workplace, leaders are forced to intervene because they normally let employees do their job (Gill, 2006). According to Limsila and Ogunlana, (2008), passive management leaders intervene only when errors occur in the work of employees because they normally wait for the difficulties of subordinates to be brought to their attention.

\section{THE MAIN COMPONENTS IN TRANSFORMATIONAL LEADERSHIP}

Transformational leadership is a current approach. In the last two decades, it has been the most influential leadership theory (Judge and Piccolo, 2004) and is one of the approaches that has attracted the attention of most researchers (Northouse, 2007).

A Full Range Leadership Model was developed by Bass (1985), a model that classifies leadership styles into three types: laissez-faire leadership, transactional leadership, and transformational leadership. Lack of leadership now characterizes laissez-faire leadership. According to Tejeda et al., (2001), transformational dimensions as well as contingent reward were positively related to leader effectiveness given that the Full Range Leadership Model was the basis for further research in leadership.

Wang and Howell (2010) developed a transformational leadership scale at a double level, based on the theoretical studies of Wu et al. (2010). This two-level transformational leadership is necessary to measure group-oriented behavior at the group level as well as to measure individual-oriented behavior at the individual level. Individual-oriented transformational leadership was significantly associated with both personal initiative and task performance, according to results obtained at the individual level of analysis. The transformational leadership that is focused on the group is significantly related to both the help behavior and the performance of the group, according to the results obtained at the level of the analysis group.

\subsection{Leaders who are transformational}

Transformational leaders focus on the personal development of followers as well as individual needs. Subordinates are encouraged by transformational leaders to achieve more than expected, according to Bass (1985). Transformational leaders, according to Bass, can accomplish this in several ways: by making subordinates increase their needs at a high level; influencing subordinates to go, for the sake of 
the organization, beyond their own personal interest and thirdly by making subordinates aware of the value and importance of objectives.

Moreover, according to Stone et al., (2004), the importance of capitalizing and appreciating subordinates is given by transformational leadership. Transformational leaders are responsible for achieving followers as well as for awakening emotion. Leaders who apply transformational leadership are concerned with employee development and progress, values, and intrinsic motivation. As a result of these concerns from transformational leaders, followers feel respect, loyalty, admiration, and trust in them (Yulk, 2010).

\subsection{Transformational leadership-the main components}

Transformational leadership is conceptualized by Bass and Avolio (2004) in that it behaviorally contains the following four main components.

The idealized influence. Idealized influence is directly correlated with the leader's ability to truly lead the way (Bass, 1985; Bass et al., 2003), to be a role model for subordinates as well as charisma (Bass, 1985; Gill, 2006). According to Bass et al. (2003), the needs of followers are considered by leaders of idealized influence over the leader's own needs. Adherents want to identify with the mission of their leaders, with the leaders themselves and are admiring them. According to Northouse (2007), subordinates are attracted to leaders with charisma precisely because of their high standards of ethical and moral conduct. The ability to connect with followers as well as to convince others belongs to charismatic leaders. Moreover, they share with their followers the risks and successes, arouse emotions but also offer a sense of purpose and a clear vision.

Inspirational motivation. Inspirational leaders, according to Yulk and Van Fleet (1982), are those leaders who "say things to build confidence in their ability to successfully perform tasks and achieve group goals and stimulate subordinates' enthusiasm for group work". This inspirational leadership causes subordinates to commit to achieving the organization's goals and at the same time inspires subordinates to work hard. In the vision of Hoyt et al. (2006), the leader's ability to build commitment and loyalty, to articulate the vision and to create in a way that inspires followers are determined by inspirational motivation. It is based on the behavior displayed by leaders, such as proper behavior modeling, generating enthusiasm as well as motivating people (Owen et al., 2004).

Intellectual stimulation. According to Bass (1985), intellectual stimulation is the leadership that motivates subordinates to be creative in solving problems and that challenges their own beliefs and thoughts. This refers to the leader's ability to challenge followers to become active participants in group decisionmaking, to be creative and innovative in problem-solving, to move forward (Hoyt et al., 2006; Limsila and Ogunlana, 2008). Intellectual stimulation includes and advertises including the demand for followers 
for new ways of doing things and for new ideas. Adherents, according to Bass et al. (2003), when faced with problems, are encouraged to develop new creative solutions and new ideas and are also included in the decision-making process.

Individualized consideration. According to Bass (1985), a particularly important aspect in the leadersubordinate relationship is the consideration for subordinates. This allows leaders to initiate and develop a particularly strong relationship with each follower. The simple exchange relationship is overcome by this relationship. According to Hoyt et al., (2006); Limsila and Ogunlana, (2008), a real concern for development, personal perspective as well as for the individual needs of followers appears in the case of leaders with individualized consideration. They, as a way of development, delegate responsibilities to followers because they especially appreciate the work done by subordinates.

\subsection{Research on transformational leadership}

Substantial and special attention was paid to transformational leadership. This is due to a significant impact on many organizational outcomes. Substantial changes within organizations can be brought about by transformational leaders (Bass, 1985). In the literature, the positive relationship between follower behavior and transformational leadership is very well documented (Camps and Rodriguez, 2011; Chen, 2004; Erkutlu, 2008; Limsila and Ogunlana, 2008; Lo et al., 2010; McGuire and Kennerly, 2006).

The relationship between individual employee performance and transformational leadership behavior is investigated, on a similar note, by Camps and Rodriguez (2011). The sample component consists of 796 faculty members from 76 university departments in Costa Rica. This study demonstrated that there is a positive relationship between the employee's perception of employment and transformational leadership behavior. The self-perceived performance of the workers, the commitment but also the employability increases due to the transformational leadership behavior. They remain dedicated to their employers who have invested in them and trusted them and also show a high self-perception of their employability to all those who work under transformational leaders. In the opinion of Camps and Rodriguez (2011), the higher performance of employees is due precisely to this high organizational commitment.

Using a sample of 92 leaders from 92 German companies, Boerner et al. (2007) identified that innovation and follower performance are significantly related to transformational leadership. By encouraging citizen organizational behavior, followers' performance is enhanced by transformational leaders. Moreover, according to Boerner et al. (2007), by triggering controversial debates among followers, their innovation is stimulated by transformational leadership. Not as strong as 


\section{Rusu, D. \\ STRATEGIES, ORGANIZATIONAL COMMITMENT AND LEADERSHIP STYLES IN SMES}

transformational leadership, the attitude of followers towards a leader but also job satisfaction are also predicted by the contingent reward.

Another study used a sample of 705 military officers stationed in 14 military units located at seven bases in Canada. According to Ivey and Kline (2010), this study showed that at all hierarchical levels transformative leadership becomes efficient and predominant in the Canadian military. Moreover, the study shows that significant contingent reward and transformative leadership have predicted effective leadership outcomes at all levels of the Canadian military. The contingent reward also predicted, not as strongly as transformative leadership, followers' attitudes toward a leader, and job satisfaction. In this way, the Canadian military could further encourage contingent rewards and transformative leadership at all levels.

It was investigated identically by Lee et al. (2011) the influence of transformational leadership on the quality of services in retail banks as well as on team performance. According to the results, transformational leadership has a critical role in the banking sector. The quality of services in banks as well as the performance of the team was positively related to the intellectual stimulation and a new dimension of transformational leadership. Improving the quality of services and team performance by encouraging followers to challenge norms and hypotheses is achieved by adopting intellectual stimulation by leaders (Lee et al., 2011).

Especially in non-Western countries (Yousef, 2000), the most widely used definition in current research for organizational engagement is formulated by Porter et al. (1974). Three psychological factors fully characterize organizational commitment: a strong desire to remain in an organization (loyalty), the desire to make a considerable effort to achieve the organizational goal (involvement) and acceptance and faith in values but also in organizational objectives (identification). Commitment can be seen, according to its different definitions, also in terms of behavior and attitude.

\section{A THREE-COMPONENT ENGAGEMENT MODEL}

In the opinion of Meyer and Allen (1997), the psychological state through which employees connect with their organization defines organizational commitment.

Affective commitment. In the opinion of Allen and Meyer (1990), due to the emotional attachment manifested towards the organization, the desire to remain an active member of an organization defines the emotional commitment. "The psychological state that characterizes the relationship between an employee and his organization" conceptualizes the emotional commitment (English et al., 2010, p. 395). According to Allen and Meyer, (1990, p. 2), the employees involved "enjoy belonging to the organization." In the opinion of Darolia et al., (2010), they are more committed to pursuing goals and identify with the organization precisely those people who show strong emotional commitments. In an 
organization, employees with an emotional commitment remain because they want to do so (Allen and Meyer, 1990).

Four factors correlated significantly with emotional engagement, according to a study by Powell and Meyer (2004): individual adjustments, personal presentation concerns, expectations, and satisfactory conditions. Affective engagement is negatively correlated with work-family conflict, stress and absenteeism, employee turnover and retirement cognitions, following a meta-analysis by Meyer et al. (2002) of the consequences, correlations and antecedents of organizational commitment. Also, this meta-analysis found that a strong positive relationship with both citizen organizational behavior and performance in the workplace characterizes the emotional commitment. They tend to engage in more interpersonal and organizational behaviors of citizenship and whenever they can make additional efforts those employees who show a high emotional commitment, according to the conclusions of Colquitt et al. (2010).

Type of normative commitment. In the opinion of Allen and Meyer (1990), due to the feeling of obligation, the desire to remain a member within an organization appears, the desire that characterizes the normative commitment. "The mentality that someone has the obligation to follow a relevant course of action for a target" (p. 316) defines, in the opinion of Meyer and Herscovitch (2001), the normative commitment. "Obligation owed and moral duty" (p. 284) are the two sides of the normative commitment, according to Meyer and Parfyonova (2010). When employees feel the feeling that it is a "moral" or a "correct" thing to remain in the organization, the normative commitment appears (Colquitt et al., 2010; Meyer and Allen, 1991).

The type of continuity commitment. According to Allen and Meyer, (1990), it is the desire for continuity expressed by a member of an organization and most often occurs due to awareness of the high cost that is associated with leaving it. In this way, because it is necessary to do this, employees continue their commitment within the organization (Meyer and Allen, 1991). What employees have given to the organization in the past is assimilated to the commitment to continuity. Employees are determined to engage in the organization by previous behavioral acts. When employees feel that if they leave, they will incur costs and if they stay they will reap benefits, the commitment to continuity appears to each other. When employees stay in their current organization, they can enjoy the benefits of seniority and high salaries, but all this, if they decide to move to another organization, can be lost. 


\section{ANTECEDENTS PRESENT IN THE ORGANIZATIONAL COMMITMENT}

The antecedents of the organizational commitment, which enumerate the roles, the characteristics of the organization, the leader-group relations, the characteristics of the position as well as the personal characteristics are stated in a meta-analysis made by Mathieu and Zajac (1990). Investment and work experiences, individual differences, demographic variables are included in the background of organizational commitment, according to the conclusions of a meta-analysis conducted by Meyer et al. (2002).

Autonomy and empowerment, recognition and feedback, fairness and fairness, clarity of purpose, interesting work and congruence are components included in the background of workplace engagement, according to Fornes et al. (2008) and according to a comprehensive review of the literature dedicated to the organizational field.

\subsection{Antecedents of organizational commitment represented by demographic factors}

Although disparate findings appear, demographic variables as predictors of engagement such as marital status, level of education, length of service, and age are used in several studies (Angle and Perry, 1981; Chughtai and Zafar, 2006; Steers, 1977). In the opinion of Stevens et al. (1978), for linking commitment to demographic variables the general arguments are based on both exchange theory and role. Various factors such as being a woman, the characteristics of the role and the increase in age increase the total cost that is associated with leaving but also with individual investments in the organization, in his opinion (Becker, 1960), according to the theory of side bets.

Age. According to Chughtai and Zafar (2006); Iqbal et al., (2011), in finding many studies the commitment is not related to age. On the contrary, age is positively related to commitment, according to the findings of several researchers (Angle and Perry, 1981; Cho and Mor Barak, 2008; Mathieu and Zajac, 1990; Rowden, 2000). Compared to younger employees, a much higher level of commitment shows older employees, according to Cho and Mor Barak (2008). Because of fewer job alternatives, older people are more engaged (Mathieu and Zajac, 1990; Mowday et al., 1982). Also, given that they have a very short history within the organization as well as much less investment compared to slightly older employees, in the opinion of Dunham et al., (1994), younger employees, compared to their own organizations show an incomparably lower commitment.

Kind. Inconsistent results regarding the relationship between commitment and gender are produced by studies that have investigated this relationship over the years. Compared to men, it has been found that women are much more engaged (Angle and Perry, 1981; Mathieu and Zajac, 1990). However, there are contrasting situations, according to a study conducted in Korea in a large corporation, conducted on a sample of 412 employees, according to which women are less dedicated in the organization than men 
(Cho and Mor Barak, 2008). According to a meta-analysis by Aydin et al. (2011) regarding the effects of gender in terms of organizational commitment, men, compared to women, have a much higher level of commitment.

Marital status. Compared to unmarried people, married employees are much more dedicated to their organization, as empirical evidence suggests (Angle and Perry, 1983; Mathieu and Zajac, 1990). Compared to employees who are unmarried because they show much more family responsibilities, married people are more employed, according to Angle and Perry (1983). The need, motivation and need of married employees to continue in that organization are generated precisely by the responsibility within the family as well as the related financial burden (Angle and Perry, 1983). Married employees are more dedicated to that organization because, for the maintenance of the family, they acutely feel the need for stability as well as the need for security in terms of jobs.

Level of education. According to the findings of several studies, the level of education and commitment are negatively related (Angle and Perry, 1983; lqbal et al., 2011; Joiner and Bakalis, 2006; Mathieu and Zajac, 1990; Rowden, 2000; Tansky et al., 1997). The much improved external work alternatives due to a higher level of education represent, for this negative correlation, a more than plausible explanation (Mathieu and Zajac, 1990). A much lower commitment to their organization is manifested by those employees who have more opportunities in terms of job change and who also have a higher education (Chughtai and Zafar, 2006; Joiner and Bakalis, 2006).

Duration of service. According to several studies, the function or duration of the service is positively related to the commitment manifested in the organizational framework (Iqbal et al., 2011; Mathieu and Zajac, 1990; Meyer and Allen, 1997; Meyer et al., 2002; Salami, 2008). According to Meyer and Allen (1997), while employees who are non-dedicated leave, according to the positive report, those who are very dedicated remain in the organization. The best and most positive predictor of employee engagement is seniority in the service (Iqbal et al. (2011). According to lqbal et al., the responsibility to the organization is greater the longer a member remains in the service. According to Meyer and Allen (1997), during their employment, employees can show and develop an emotional attachment to that organization. It becomes much more difficult for the employee to change jobs because This emotional attachment is enhanced in the long run (Iqbal et al., 2011; Meyer and Allen, 1997.) It can be considered as a personal investment of the employee in an organization all those years he spent in the organization.

Representative leadership styles. A precedent for organizational commitment is represented precisely by the leadership style, according to the empirical evidence generated by a lot of research in this regard. A positive link between organizational commitment and leadership styles is constantly shown 
through a number of previous research using various leadership measures. According to Yousef, (2000), when leaders adopt participatory or consultative leadership behavior, their employees perform much higher in the workplace, are much more satisfied with their jobs, and become more dedicated to their organizations.

Organizational engagement is positively related to leadership behaviors (Yiing and Ahmad, 2009). The scale of affective commitment as well as the leadership behavior questionnaire (LBDQ) developed by Allen and Meyer (1990) were administered to 238 employees present in different career environments in Malaysia. It has been found that employees in their organization, when their leaders adopt participatory leadership, directive and supportive behaviors, are very involved and very dedicated.

Lok and Crawford (2004) found in a study of 337 managers in Australia and Hong Kong between the ages of 26 and 45 that leadership styles are a particularly important background. of organizational commitment. The results showed that the level of employee engagement is positively influenced by the attention management style.

Dale and Fox (2008) investigated the organizational commitment shown by a large manufacturing corporation based in the Midwest. This study was based on a sample of 147 full-time employees and their ages ranged from 21 to 59 years. The OCQ scale with nine articles by Mowday et al. (1979) was used and LBDQ. According to this study, leadership styles (consideration and initiative structure) are positive predictors of organizational commitment.

However, a study by Awan and Mahmood (2010) provided a result contrary to expectations. Based on a sample of 115 professional librarians present at 30 universities in Pakistan, they studied the possibility of the impact of leadership style on employee engagement. The research used the T-P Leadership Questionnaire, consisting of 35 elements derived from the LBDQ to measure autocratic and laissez-faire leadership styles. The study also used 15 structured statements in a questionnaire on employee engagement to measure the level of organizational commitment present among employees. According to the results obtained, most of the chief librarians are particularly dedicated to organizations and put into practice the autocratic leadership style. Even in these conditions, no connection was identified between employee commitment and leadership style.

\subsection{Results of organizational commitment}

There is a positive relationship between organizational commitment and many positive work results. "The driving force behind an organization's performance" (p. 408) is organizational commitment, according to Suliman and lles (2000). Organizational engagement is positively related to organizational civic behavior (Riketta, 2002), motivation (Mathieu and Zajac, 1990) as well as professional satisfaction 
(Angle and Perry, 1981; Chughtai and Zafar, 2006; Meyer et al., 2002; Mowday and et al., 1979; Pool and Pool, 2007; Porter et al., 1974).

The impact of organizational commitment on the financial performance of 202 companies listed on the Kuala Lumpur Stock Exchange was investigated by Abdul Rashid et al. (2003). According to the results obtained, most of the respondents (62.4\%) have a continuous commitment, $32 \%$ of the respondents have an emotional commitment and $6 \%$ of the respondents have a normative commitment. Organizational commitment, in accordance with the results obtained, shows a significant influence in terms of performance.

According to Chen et al. (2006), organizational commitment also had a positive influence on workplace performance. Organizational engagement, according to other studies, is negatively related to turnover rate (Angle and Perry, 1981; Chughtai and Zafar, 2006; Porter et al., 1974) and absenteeism (Angle and Perry, 1981; Farrel and Stamm, 1988). Organizational commitment, according to Yousef (2000), is positively related to both performance and job satisfaction. Yiing and Ahmad (2009), in contrast to Yousef (2000), found that organizational commitment is negatively correlated with job satisfaction.

\section{THE LINK BETWEEN ORGANIZATIONAL COMMITMENTS AND TRANSFORMATIONAL LEADERSHIP STYLES}

The relationship between organizational commitment and transformational leadership style is examined by many studies. Organizational engagement shows a weak positive correlation with both transactional and transformational behaviors. Organizational engagement, to the detriment of other leadership behaviors, was more correlated with individual leadership behavior, inspirational motivation, and idealized influence. According to Chen, organizational commitment is more related to transformational leadership behavior, to the detriment of transactional leadership behaviors.

Within the construction industry in Thailand, a study was conducted by Limsila and Ogunlana (2008). According to this study, a transformative leadership style has a positive impact on the organizational commitment of subordinates as well as on work performance. Transformative leadership style has a significant association with leadership and leadership outcomes (extra effort, satisfaction and effectiveness). According to the results obtained, while laissez-faire and transactional leaders cannot obtain commitment from subordinates, transformational leaders can obtain commitment from them.

A study based on a sample of 118 employees of a US subsidiary in Sarawak, Malaysia was conducted by Ismail et al. (2011). Based on the habilitation literature as well as the modified articles from MLQ, $O C Q$, the questionnaires were elaborated in order to measure the habilitation, the organizational commitment as well as the transformative leadership. The results obtained from the study highlighted 
the fact that the transformational leadership was correlated in a significantly positive way both with the organizational commitment of the employees and with the empowerment. Transformational leaders, in the respondents' perception, increased the empowerment of employees and subsequently increased the level of organizational commitment present among employees.

A positive impact regarding the organizational commitment manifested by the subordinates and the work performance has the transformational leadership style. A significant association with leadership commitment and outcomes (extra effort, satisfaction and effectiveness) is the transformational leadership style. Laissez-faire and transactional leaders cannot obtain commitment from subordinates over time, transformational leaders do. Both transactional management and transformational management have a positive impact on organizational commitment (Lee, 2005). With one dimension of LMX has a negative association transactional management: loyalty. Normative and affective commitment have beneficial links with transformational leadership.

\section{CONCLUSIONS}

It is especially necessary to investigate the level of commitment present among employees but also the effectiveness of management, in the context of reforms and changes in many countries, in higher education. In this way, with the various reforms and changes in higher education in many countries, it becomes particularly important for universities to investigate the effectiveness of management but also the level of commitment among employees. Meyer and Allen (1997) in organizational engagement theory suggest that "organizations will be in a better position to anticipate the impact of change and for better and more efficient management, understanding how it helps shape behaviors and attitudes and how and especially when commitments develop "(p. ix).

Issues in developed countries are addressed by literature reviews on organizational commitment and leadership. In developing countries very few studies have been conducted on this topic. Moreover, in higher education institutions, relatively limited studies have been conducted on organizational commitment and leadership styles. Briefly, the present review relates the full-range model (Bass, 1985) as well as the conceptual framework that includes laissez-faire leadership, transactional leadership, and transformational leadership. This article also presented the characteristics and abilities of transformational leaders.

In terms of organizational engagement, this article also provides a review of the literature. Different definitions regarding the three-component engagement model and organizational engagement are presented and described in this section. 


\section{REFERENCES}

Abdul Rashid, M.Z., Sambasivan, M. and Johari, J. (2003), "The influence of corporate culture and organizational commitment on performance", Journal of Management Development, 22(8): 708-728. doi: 10.1108/02621710310487873.

Angle, H. and Perry, J. (1981), "An empirical assessment of organizational commitment and organizational effectiveness", Administrative Science Quarterly, 26(2): 1-13.

Angle, H. and Perry, J. (1983), "Organizational commitment: individual and organizational influences", Work and Occupations, 10(2): 123-146.

Avery, G.C. (2004), Understanding Leadership, Sage Publications Inc., Thousand Oaks, CA.

Awan, M.R. and Mahmood, K. (2010), "Relationship among leadership style, organizational culture and employee commitment in university libraries", Library Management, 31(4/5): 253-266. doi: 10.1108/01435121011046326.

Aydin, A., Sarier, Y. and Uysal, S. (2011), "The effect of gender on organizational commitment of teachers: a meta analytic analysis", Educational Sciences: Theory \& Practice, 11(2): 628-632.

Bass, B.M. (1989), "The two faces of charismatic leadership", Leaders Magazine, 12(4): 44-45.

Bass, B.M. and Avolio, B.J. (Eds) (1994), Improving Organizational Effectiveness Through Transformational Leadership, Sage Publications, Thousand Oaks, CA.

Bass, B.M. and Avolio, B.J. (2004), Multifactor Leadership Questionnaire: Manual and Sample Set, 3rd ed., Mind Garden, Redwood City, CA.

Camps, J. and Rodriguez, H. (2011), "Transformational leadership, learning, and employability: effects on performance among faculty members", Personnel Review, 40(4): 423-442. doi: 10.1108/00483481111133327.

Chen, J., Silverthorne, C. and Hung, J. (2006), "Organization communication, job stress, organizational commitment, and job performance of accounting professionals in Taiwan and America", Leadership \& Organization Development Journal, 27(4): 242-249. doi: 10.1108/01437730610666000.

Chen, L.Y. (2002), "An examination of the relationship between leadership behavior and organizational commitment at steel companies", The Journal of Applied Management and Entrepreneurship, 7(2): 122-142.

Chew, J. and Chan, C.C.A. (2008), "Human resource practices, organizational commitment and intention to stay", International Journal of Manpower, 29(6): 503-522. doi: 10.1108/01437720810904194.

Cho, S. and Mor Barak, M.E. (2008), "Understanding of diversity and inclusion in a perceived homogeneous culture: a study of organizational commitment and job performance among Korean employees", Administration in Social Work, 32(4): 100-126. doi: 10.1080/ 03643100802293865.

Dale, K. and Fox, M.L. (2008), "Leadership style and organizational commitment: mediating effect of role stress", Journal of Managerial Issues, 20(1): 109-130.

Darolia, C.R., Kumari, P. and Darolia, S. (2010), "Perceived organizational support, work motivation, and organizational commitment as determinants of job performance", Journal of the Indian Academy of Applied Psychology, 36(1): 69-78.

Dunham, R.B., Grube, J.A. and Castaneda, M.B. (1994), "Organizational commitment: the utility of an integrative definition", Journal of Applied Psychology, 79(2): 370-380. 


\section{Rusu, D. \\ STRATEGIES, ORGANIZATIONAL COMMITMENT AND LEADERSHIP STYLES IN SMES}

English, B., Morrison, D. and Chalon, C. (2010), "Moderator effects of organizational tenure on the relationship between psychological climate and affective commitment", Journal of Management Development, 29(4): 394-408. doi: 10.1108/02621711011039187.

Erhart, M.G. and Nauman, S.E. (2004), "Organizational citizenship behavior in work groups: a group norms approach", Journal of Applied Psychology, 89(6): 960-974.

Farrel, D. and Stamm, C.L. (1988), "Meta-analysis of the correlates of employee absence", Human Relations, 41(2): 221-227.

Fornes, S.L., Rocco, T.S. and Wollard, K.K. (2008), "Workplace commitment: a conceptual model developed from integrative review of the research", Human Resource Development Review, 7(3): 339-357. doi: 10.1177/1534484308318760.

Hoyt, C.L., Goethals, G.R. and Riggio, R.E. (2006), "Leader-follower relations: group dynamics and the role of leadership", in Goethals, G.R. and Sorenson, G.L.J. (Eds), The Quest for a General Theory of Leadership, Edward Elgar Publishing Inc., Cheltenham, pp. 96-122.

Ibanescu, A., Racolta-Paina, D., N., lonescu, D., (2015), Manager's perceptions regarding management challenges and the development of Romanian SMEs. Selected findings from 2021-2015, On-line Journal Modelling the New Europe, Issue no. 16/2015.

Ioniță, M., Stoica, A., M., (2019), Leadership in a Romanian Franchise Organization, Management and the economic crysis, 30 .

Ismail, A., Mohamed, H.A., Sulaiman, A.Z., Mohamad, M.H. and Yusuf, M.H. (2011), "An e pirical study of the relationship between transformational leadership, empowerment and organizational commitment", Business and Economics Research Journal, 2(1): 89-107.

Ivey, G.W. and Kline, T.J.B. (2010), "Transformational and active transactional leadership in the Canadian military", Leadership \& Organization Development Journal, 31(3): 246-262. doi: 10.1108/01437731011039352.

Kumar, C.R. and Kaptan, S.S. (2007), The Leadership in Management: Understanding Leadership Wisdom, APH Publishing, New Delhi.

Lee, P.K.C., Cheng, T.C.E., Yeung, A.C.L. and Lai, K. (2011), "An empirical study of transformational leadership, team performance and service quality in retail banks", Omega, 39(3): 690-701. doi: 10.1016/j.omega.2011.02.001.

Lok, P. and Crawford, J. (1999), "The relationship between commitment and organizational culture, subculture, leadership style and job satisfaction in organizational change and development", Leadership \& Organization Development Journal, 20(7): 365-373.

Lok, P. and Crawford, J. (2004), "The effect of organizational culture and leadership style on job satisfaction and organizational commitment: a cross-national comparison", Journal of Management Development, 23(4): 321-338. doi: 10.1108/02621710410529785.

McGuire, E. and Kennerly, S.M. (2006), "Nurse managers as transformational and transactional leaders", Nursing Economics, 24(4): 179-185.

Mandruleanu, A., (2012), The impact of integrators on the organizational intellectual capital, Management \& Marketing Challenges for the Knowledge Society , 7(3): 415-436.

Meyer, J.P. and Allen, N.J. (1984), "Testing the side-bet theory of organizational commitment: some methodological considerations", Journal of Applied Psychology, 69(2): 372-378.

Meyer, J.P. and Allen, N.J. (1997), Commitment in the Workplace, Sage publications, London.

Meyer, J.P. and Herscovitch, L. (2001), "Commitment in the workplace: toward a general model", Human Resource Management Review, 11(4): 299-326. 
Meyer, J.P. and Parfyonova, N.M. (2010), "Normative commitment in the workplace: a theoretical analysis and re-conceptualization", Human Resource Management Review, 20(4): 283-294. doi: 10.1016/j.hrmr.2009.09.001.

Mihai, L., Schiopoiu, B., A., Mihai, M., (2017), Comparison of the leadership styles practiced by Romanian and Dutch SME owners, International Journal of Organizational Leadership 6: 4-16.

Nicolescu, O., Verboncu, I., Nicolescu, C., (2012), SMEs Romanian Managers Training in the EU Context - Results of the 1988 Interviews, Review of International Comparative Management Volume 13, Issue 2, May 2012189.

Paunescu, C., Popescu, C., M., Duennweber, M., (2018), Factors Determining Desirability of Entrepreneurship in Romania, Sustainability 2018, 10, 3893; doi:10.3390/su10113893.

Pool, S. and Pool, B. (2007), "A management development model: measuring organizational commitment and its impact on job satisfaction among executives in a learning organization", Journal of Management Development, 26(4): 353-369. doi: 10.1108/ 02621710710740101.

Porter, L.W., Steers, R.M., Mowday, R.T. and Boulian, P.V. (1974), "Organizational commitment, job satisfaction, and turnover, among psychiatric technicians", Journal of Applied Psychology, 59(5): 603-609.

Riketta, M. (2002), "Attitudinal organizational commitment and job performance: a metaanalysis", Journal of Organizational Behavior, 23(5): 257-266.

Rowden, R.W. (2000), "The relationship between charismatic leadership behaviors and organizational commitment", Leadership \& Organization Development Journal, 21(1): 30-35.

Salami, S.O. (2008), "Demographic and psychological factors predicting organizational commi ment among industrial workers", Anthropologist, 10(5): 31-38.

Samad, S. (2005), "Unraveling the organizational commitment and job performance relationship: exploring the moderating effects of job satisfaction", The Business Review, Cambridge, 4(2): 79-84.

Steers, R.M. (1977), "Antecedents and outcomes of organizational commitment", Administrative Science Quarterly, 22(1): 46-56.

Stone, A.G., Russell, R.F. and Patterson, K. (2004), "Transformational versus servant leadership: a difference in leader focus", The Leadership \& Organization Development Journal, 25(4): 349-361. doi: 10.1108/01437730410538671.

Suliman, A. and lles, P. (2000), "Is continuance commitment beneficial to organizations? Commitmentperformance relationship, a new look", Journal of Managerial Psychology, 15(1): 407-422.

Tapurica, C., O., (2012), Proceedings of the $8^{\text {th }}$ European Conference on Management, Leadership, and Governance.

Tejeda, M.J., Scandura, T.A. and Pillai, R. (2001), "The MLQ revisited: psychometric properties and recommendations", Leadership Quarterly, 12(2): 31-52.

Trifu, A., (2018), Ceo-Leaders and Ceo-Managers face to the firm's evolution, Quality-Access to Success, Vol. 19, S3, October 2018.

Wu, F.Y. (2009), "The relationship between leadership styles and foreign English teacher's job satisfaction in adult English cram schools: evidences in Taiwan", The Journal of American Academy of Business, 14(2): 75-82.

Wu, W., Liu, Y., Song, L.J. and Liu, J. (2006), "Effects of organizational leadership on employee commitment: the moderating role of emotional intelligence", Journal of Psychology in Chinese Societies, 7(2): 283-306. 
Rusu, D.

STRATEGIES, ORGANIZATIONAL COMMITMENT AND LEADERSHIP STYLES IN SMES

Yiing, L.H. and Ahmad, K.Z. (2009), "The moderating effects of organizational culture on the relationship between leadership behavior and organizational commitment and between organizational commitment and job satisfaction and performance", Leadership \& Organization Development Journal, 30(1): 53-86. doi: 10.1108/01337730910927106.

Yousef, D.A. (2000), "Organizational commitment: a mediator of the relationships of leadership behavior with job satisfaction and performance in a non-western country", Journal of Managerial Psychology, 15(1): 6-28. 